\title{
Real-time prognosis of flowing bottom-hole pressure in a vertical well for a multiphase flow using computational intelligence techniques
}

\author{
Zeeshan Tariq $^{1}$ D $\cdot$ Mohamed Mahmoud $^{1} \cdot$ Abdulazeez Abdulraheem $^{1}$
}

Received: 31 October 2018 / Accepted: 10 July 2019 / Published online: 18 July 2019

(c) The Author(s) 2019

\begin{abstract}
An accurate prediction of well flowing bottom-hole pressure (FBHP) is highly needed in petroleum engineering applications such as for the field production optimization, cost per barrel of oil reduction, and quantification of workover remedial operations. A good number of empirical correlations and mechanistic models exist in the literature and are frequently used in oil industry to estimate FBHP. But majority of the empirical models were developed under a laboratory scale and are therefore inaccurate when scaled up for the field applications. The objective of this study is to present a new computational intelligence-based model to predict FBHP for a naturally flowing vertical well with multiphase flow. The present study shows that the accuracy of FBHP estimation using PSO-ANN is better than the conventional ANN model. A small average absolute percentage error of less than $2.1 \%$ is observed with the proposed model, while comparing the previous empirical correlations and mechanistic models on the same data gives more than $15 \%$ error. The new model is trained on a surface production data, which makes the prediction of FBHP in a real time. A group trend analysis tests were also carried out to assure that the proposed model is accurately capturing the underline physics behind the problem.
\end{abstract}

Keywords Flowing bottom-hole pressure $\cdot$ Real time $\cdot$ Artificial neural network $\cdot$ Particle swarm optimization $\cdot$ Empirical model $\cdot$ Vertical well

$\begin{array}{ll}\text { Abbreviations } \\ \text { AAPE } & \text { Average absolute percentage error } \\ \text { ANFIS } & \text { Adaptive neuro-fuzzy interference system } \\ \text { ANN } & \text { Artificial neural network } \\ \text { API } & \text { American Petroleum Institute } \\ \text { BHP } & \text { Bottom-hole pressure (Psia) } \\ \text { BTM } & \text { Bottom-hole temperature }\left({ }^{\circ} \text { F) }\right. \\ \text { CC } & \text { Correlation coefficient } \\ \text { CI } & \text { Computational intelligence } \\ \text { FBHP } & \text { Flowing bottom-hole pressure (Psia) } \\ \text { FFNN } & \text { Feed-forward neural network } \\ \text { GLR } & \text { Gas-liquid ratio } \\ \text { GMDH } & \text { Group method of data handling }\end{array}$

Zeeshan Tariq

g201406240@kfupm.edu.sa

Mohamed Mahmoud

mmahmoud@kfupm.edus.sa

Abdulazeez Abdulraheem

aazeez@kfupm.edu.sa

1 Department of Petroleum Engineering, College of Petroleum and Geosciences, King Fahd University of Petroleum and Minerals, Dhahran 31261, Saudi Arabia

$\begin{array}{ll}\text { ID } & \text { Internal diameter } \\ \text { IPR } & \text { Inflow performance relationship } \\ \text { LM } & \text { Levenberg-Marquardt learning algorithm } \\ \text { Logsig } & \text { Logistic sigmoid activation/transfer function } \\ \text { PETE } & \text { Petroleum engineering } \\ \text { PSO } & \text { Particle swarm optimization } \\ P_{\text {wh }} & \text { Wellhead pressure (Psia) } \\ \text { RMSE } & \text { Root-mean-square error } \\ \text { STM } & \text { Surface temperature }\left({ }^{\circ} \text { F) }\right. \\ \text { Std } & \text { Standard deviation } \\ \text { SVM } & \text { Support vectors regression } \\ \text { Tansig } & \text { Tangential sigmoid activation/transfer function } \\ x & \text { Input parameters } \\ y & \text { Output variable }\end{array}$

\section{List of symbols}

$\alpha \quad$ Learning rate

$b_{1} \quad$ Biases vector between the input layer and the single hidden layer of ANN

$b_{2} \quad$ Bias value between the single hidden layer and an output layer of ANN

$c_{1} \quad$ Cognitive parameter $\left(0 \leq c_{1} \leq 1.2\right)$

$c_{2} \quad$ Cognitive parameter $\left(0 \leq c_{2} \leq 1.2\right)$

$E_{\max } \quad$ Maximum error 


$\begin{array}{ll}E_{\mathrm{min}} & \text { Minimum error } \\ i & \text { Index used for total number of neurons } \\ j & \text { Index used for number of inputs } \\ J & \text { Total number of input parameters } \\ n & \text { Normalized value } \\ N_{\mathrm{h}} & \text { Total number of neurons } \\ N_{\mathrm{p}} & \text { Total number of input parameters } \\ p_{i} & \text { Particle } i \text { position at any iteration } \\ p_{i}^{b} & \text { Particle best solution } \\ p_{\mathrm{gb}} & \text { Global best solution } \\ q_{\mathrm{o}} & \text { Oil production rate (bbls/day) } \\ q_{\mathrm{g}} & \text { Gas production rate (MScf/day) } \\ q_{\mathrm{w}} & \text { Water production rate (bbls/day) } \\ R^{2} & \text { Coefficient of determination } \\ v_{i} & \text { Particle velocity } \\ w_{1} & \text { Weights matrix between the input layer and the } \\ & \text { single hidden layer of ANN } \\ w_{2} & \text { Weights vector between the single hidden layer } \\ & \text { and an output layer of ANN } \\ x & \text { Input parameters } \\ y & \text { Output variable } \\ \sigma_{\mathrm{o}} & \text { A transfer function between the hidden layer and } \\ & \text { an output layer of FFNN } \\ \sigma_{\mathrm{L}} & \text { A transfer function between the input layer and } \\ \emptyset & \text { the hidden layer of FFNN } \\ \omega & \text { Tubing internal diameter (inches) } \\ & \text { Weight (0 } \leq w \leq 1.2)\end{array}$

\section{Introduction}

Estimation of well bottom-hole pressure at any existing operating conditions is continuously needed in oil and gas wells to monitor fluid movements inside the wellbore and the nearby wellbore regions. Petroleum wells normally produce a mixture of liquids and gases at the surface. The phase distribution typically changes due to the pressure variations along the course of the flow. At pressure above the bubble point pressure of the liquid phase, particularly at the bottom of the well, the flow is the single phase, i.e., oil phase only, but as oil moves up inside the vertical well, the hydrostatic pressure drop causes liberation of gases from the oil phase which resulted in the multiphase flow of oil and gas (Hagedorn and Brown 1965; Govier and Fogarasi 1975). Multiphase flow is a simultaneous flow of two or three phases such as oil, gas, and water which can start producing any time in the life of well (Beggs and Brill 1973). Multiphase flow phenomenon has also gained considerable attention in many other science fields including mechanical, civil, chemical, and nuclear engineering (Jahanandish et al. 2011). The representative prediction of the pressure drop in a vertical well during the simultaneous multiphase flow of fluids is a well-known problem in the petroleum industry (Hagedorn and Brown 1965). The need to properly estimate pressure drop in a vertical well is very necessary for the accurate forecast of production performances and for the appropriate well completions design and artificial-lift systems (Ansari et al. 1994).

Nowadays, smart well completion is very common, in which down-hole pressure gauges are permanently installed at the bottom of the well to measure FBHP. However, these pressure gauges need constant calibration and maintenance to prevent malfunctioning and misleading readings (Davies and Aggrey 2007; Al-Shammari 2011). In case of conventional well completions, frequently intervening a well to measure FBHP is an exhaustive job which is linked with several risks like production interruptions and economic losses. For these purposes, the real-time information of FBHP is very handy for production engineers.

Numerous mechanistic and empirical models were developed to estimate the pressure drop inside the tubing in a vertical well. Most of the empirical models and correlations were formulated under laboratory scale, which eventually become less accurate when up-scaled to field situations (Pucknell et al. 1993). The most commonly used correlations are Duns and Ros (1963); Hagedorn and Brown (1965); Aziz and Govier (1972); Beggs and Brill (1973); and Mukherjee and Brill (1983). Several studies have shown that these empirical correlations estimate pressure drop in multiphase flowing wells with large errors and high level of uncertainty (Asheim 1986; Pucknell et al. 1993; Takacs 2001; Lawson and Brill 1974). Mechanistic models are based on theoretical approaches to calculate multiphase flow characteristics such as mixture densities, flow patterns, and liquid hold ups. The most commonly used mechanistic models in petroleum engineering calculations are Kabir and Hasan (1986), Ansari et al. (1994), Chokshi et al. (1996), and Gomez et al. (1999).

The past two decades have seen significant increase in computational intelligence (CI) applications in various areas of geosciences and petroleum engineering (PETE). The relevance of CI in PETE applications stems from CI's ability to handle the huge streams of data generated in the field such as seismic data, petrophysical well log data, and injection and production data. Every wiggle in the log and every blip in the data signify something and have the potential to be used in addressing pertinent issues. Also, in the real world, the basic assumptions used in the derivation of the physical equations may be violated, due to numerous reasons such as anisotropy, heterogeneity, nonlinearity, nonelasticity, and nonideal fluid behavior. CI can address such complications with relative ease (Anifowose et al. 2017). Some of the domains of the petroleum engineering in which CI techniques brought new innovations include porosity-permeability predictions (Abdulraheem et al. 2007; El-Sebakhy et al. 2012; Nooruddin et al. 2013; Helmy et al. 2013; Anifowose et al. 2013, 2014, 2017), hydraulic flow unit identification (Shujath Ali 
et al. 2013), rock mechanical parameters estimation (Yang and Rosenbaum 2002; Sonmez et al. 2004; Abdulraheem et al. 2009; Cevik et al. 2011; Tariq et al. 2018b), missing petrophysical well logs estimation (Tariq et al. 2019), welltesting parameters estimation (Artun 2017; Bazargan and Adibifard 2017), asphaltene and wax precipitation predictions (Rezaian et al. 2010; Adeyemi and Sulaimon 2012; Fattahi et al. 2015; Alimohammadi et al. 2017), water saturation prediction (Adebayo et al. 2015; Bageri et al. 2015; Baziar et al. 2016, 2018; Khan et al. 2018), gas compressibility factor (Mohagheghian et al. 2015; Tariq and Mahmoud 2019), oil well drilling rate of penetration optimization (Gidh et al. 2012), and many other oil and gas applications (Ashena et al. 2010; Jahanandish et al. 2011; Asoodeh 2013; Rammay and Abdulraheem 2016).

An artificial neural network (ANN) is one of the most powerful and robust CI tools for solving complex nonlinear problems, including function approximation, pattern recognition, parameter selection, and automated control and optimization (Maren 1990; Huang et al. 1996). This technique is originated from the learning principles of biological neurons found in human body (Graves et al. 2009). Recent advances in the mathematics of neural network and its ability to solve complex and nonlinear problems have gained wide recognition in the petroleum industry (Anifowose et al. 2014).

Petroleum industry has paid significant attention to use $\mathrm{CI}$ technique to predict FBHP in oil and gas wells. Osman et al. (2005) developed the model for estimating bottomhole flowing pressure using artificial intelligence (AI) tools. Their model was based on 300 data points. Jahanandish et al. (2011) presented an ANN model for the estimation of the BHP. Their model was developed on 413 data points. AlShammari (2011) predicted BHP using adaptive neuro-fuzzy interference system (ANFIS) on 596 data points obtained from Middle Eastern fields. He used Genfis-2 (subtractive clustering) to develop ANFIS model for BHP prediction. Bello and Asafa (2014) predicted the FBHP and bottom-hole temperature using functional network technique. They have used 200 data points from multiple wells. Li et al. (2014) designed a calculation procedure to predict BHP using multiphase correlation and trained ANN model. They predicted BHP with 23\% average absolute percentage error (AAPE) and 0.176 std. Ebrahimi and Khamehchi (2015) used ANN technique on the data obtained from Middle Eastern field to improve the prediction of BHP. Their objective was to test several optimization algorithms to optimize ANN parameters and then compare their results with conventional methods in oil and gas industry. Memon et al. (2015) created dynamic well surrogate reservoir models (SRM) to predict flowing well bottom-hole pressure using radial basis function neural network (RBF). The input data of their model were porosity and permeability of different layers in SRM and production rate. The output data of their model were extorted from a SRM model. Ayoub et al. (2015) presented the model to predict the pressure drop in a multiphase flow vertical well using the group method of data-handling (GMDH) approach. The GMDH is a commonly used regression technique based on constructing high-order polynomials (Karnazes and Bonnell 1982; Assaleh et al. 2013). Ahmadi et al. (2016) predicted FBHP at different time steps for an initially undersaturated reservoir using surrogated reservoir modeling and radial basis neural network approach. They have used the output of reservoir simulator such as oil rate, gas rate, and saturation to predict FBHP. Chen et al. (2017) used support vector regression (SVR) to predict FBHP in gas wells. They have used the measured FBHP data from Sulige gas field as an output parameter. Their model was based on the well perforation depth, flowing water rate, flowing gas rate, relative gas density, average wellbore temperature, casing pressure, and gas compressibility factor.

It can be inferred from the literature survey that CI methods can be applied to estimate FBHP. The previous analytical and mechanistic models (Duns and Ros 1963; Hagedorn and Brown 1965; Beggs and Brill 1973; Mukherjee and Brill 1985; Kabir and Hasan 1986; Ansari et al. 1994; Gomez et al. 1999) are built on the parameters which can be determined from the laboratory analysis. This means that they are not capable of giving real-time FBHP values under existing operating conditions. Also, these models are computationally very expensive to execute. Two major problems with the previous works are going to be addressed in this study. Firstly, previous CI research studies predicted the FBHP using laboratory-dependent inputs, so the first objective is to identify the real-time input parameters that are readily available on the surface to estimate the real-time FBHP with good accuracy. Secondly, previous researchers (Osman et al. 2005; Davies and Aggrey 2007; Jahanandish et al. 2011; AlShammari 2011; Adebayo et al. 2013; Bello and Asafa 2014; Memon et al. 2014, 2015; Li et al. 2014; Ayoub et al. 2015; Ebrahimi and Khamehchi 2015; Awadalla and Yousef 2016; Chen et al. 2017) proposed a black box type of CI models. In all these papers, authors only mentioned the approach they have used to train their models. Readers of their papers cannot use them to predict FBHP on a new dataset, so the second objective is to develop robust ANN-based mathematical model to predict real-time flowing bottom-hole pressure (FBHP) by using real-time surface production data parameters. To improve the accuracy of the ANN model, particle swarm optimization (PSO) algorithm is used to optimize the weights and biases of the trained neural network to predict FBHP; previously, Ebrahimi and Khamehchi (2015) and Awadalla and Yousef (2016) used optimization algorithms to optimize the parameters of ANN model. In this study, ANN model is translated into simple mathematical model by extracting optimized weights and biases. This will allow

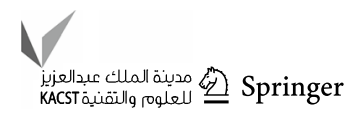


readers to use proposed model without the need for any CI software.

\section{Methodology}

\section{Data acquisition and preprocessing}

Data analysis and preprocessing are the key steps to perform carefully, since the prediction performance of CI models is highly dependent on the quality of the data. A total of 206 data points were obtained from published sources (Govier and Fogarasi 1975; Asheim 1986). In these sources, the pressure data were obtained from the BHP surveys by lowering the down-hole pressure gauges inside the well just above the perforations to record the well bottom-hole flowing pressure. Table 1 lists some of the data points used for FBHP prediction modeling. To scrutinize the quality of the obtained data and to remove any suspicious outliers, various mechanistic and empirical models were used to predict the FBHP and their results were then compared with the measured actual values. Data points which constantly caused poor predictions by all mechanistic models and correlations were assumed to be erroneous and therefore deleted. The mechanistic and empirical models used to check the quality of the data were Duns and Ros (1963), Hagedorn and Brown (1965), Beggs and Brill (1973), Mukherjee and Brill (1985), Kabir and Hasan (1986), Ansari et al. (1994), and Gomez et al. (1999).

\section{Data analysis and description}

The real-time production data used in this study were taken from the perfectly vertical wells with no any form of artificial lift, and all wells were completely naturally flowing. FBHP was measured at the depth of perforation. Dataset consists of total of nine input parameters such as well perforation depth, flowing oil rate $\left(q_{\mathrm{o}}\right)$, flowing gas rate $\left(q_{\mathrm{g}}\right)$, flowing water rate $\left(q_{\mathrm{g}}\right)$, production tubing internal diameter $(\emptyset)$, surface temperature (STM), well bottom-hole temperature (BTM), oil gravity (API), and wellhead pressure $\left(P_{\mathrm{wh}}\right)$. The output is measured FBHP. The ranges of input parameters employed are perforation depth, 4500-7550 ft, $q_{\mathrm{o}}$, 280-19,800 bbl/day, $q_{\mathrm{g}}$, 33.6-27,400 MScf/D , $q_{\mathrm{g}}, 0-11,000$ bbl/day, $\emptyset, 1.995-4.000$ inches, STM, 76-160 ${ }^{\circ} \mathrm{F}$, BTM, $157-215^{\circ} \mathrm{F}$, and $P_{\mathrm{wh}}, 80-960 \mathrm{psia}$. The ranges of all investigated input parameters are considered practically reasonable in the petroleum field and are comparable with previously published studies. A complete statistical description of the data used in the training of the model is given in Table 2.

The next most imperative step taken in the data analysis process of this study was to determine the relative importance (in terms of correlation coefficient (CC)) of each input parameter with the FBHP. The CC was calculated between

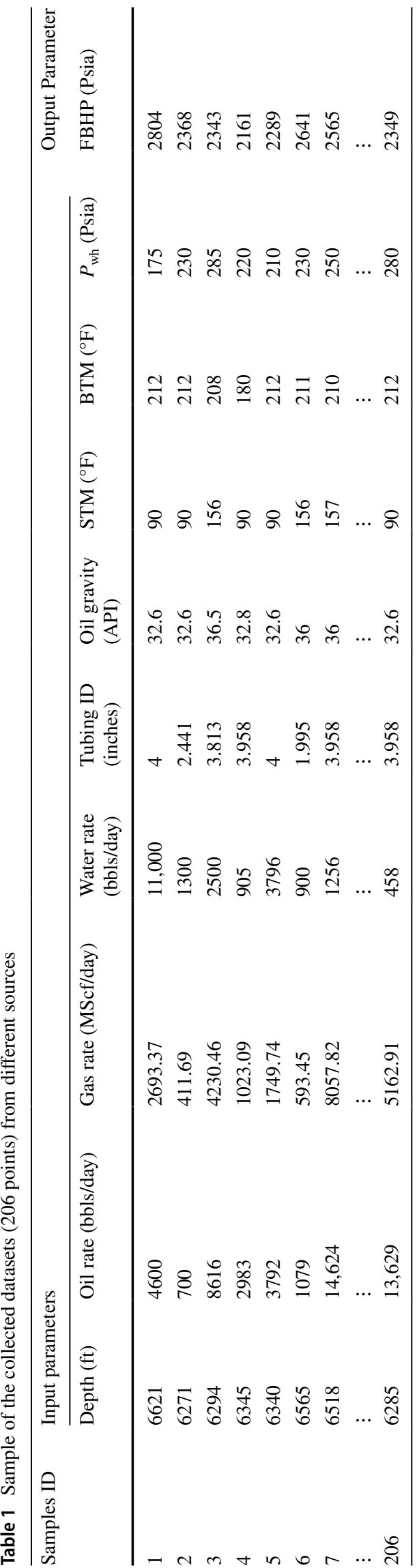


Table 2 Statistical description of (a) training dataset and (b) testing dataset

\begin{tabular}{|c|c|c|c|c|c|c|c|}
\hline Variables & Minimum & Maximum & Mean & Range & SD & Kurtosis & Skewness \\
\hline \multicolumn{8}{|l|}{ (a) Training dataset } \\
\hline \multicolumn{8}{|l|}{ Inputs } \\
\hline Depth (ft) & 4550.00 & 7100.00 & 6361.04 & 2550.00 & 563.49 & -1.66 & 1.98 \\
\hline Oil rate (bbls/day) & 280.00 & $19,618.00$ & 6497.97 & $19,338.00$ & 5101.40 & 0.76 & -0.54 \\
\hline Gas rate (Mscf/day) & 33.60 & $13,562.20$ & 3595.11 & $13,528.60$ & 3301.76 & 1.12 & 0.59 \\
\hline Water rate (bbls/day) & 0.00 & $11,000.00$ & 2494.76 & $11,000.00$ & 2580.46 & 0.90 & 0.01 \\
\hline Tubing diameter (inches) & 2.00 & 4.00 & 3.65 & 2.01 & 0.62 & -1.86 & 1.85 \\
\hline Oil gravity (API) & 30.00 & 37.00 & 33.96 & 7.00 & 2.37 & -0.06 & -1.35 \\
\hline Surface temperature $\left({ }^{\circ} \mathrm{F}\right)$ & 76.00 & 160.00 & 120.31 & 84.00 & 31.28 & 0.16 & -1.88 \\
\hline Bottom-hole temperature $\left({ }^{\circ} \mathrm{F}\right)$ & 161.00 & 215.00 & 203.94 & 54.00 & 16.60 & -1.96 & 2.14 \\
\hline Wellhead pressure (Psi) & 80.00 & 960.00 & 324.29 & 880.00 & 153.49 & 1.37 & 1.95 \\
\hline \multicolumn{8}{|l|}{ Output } \\
\hline Flowing bottom-hole pressure (Psi) & 1227.00 & 3124.00 & 2483.88 & 1897.00 & 293.08 & -0.54 & 1.28 \\
\hline \multicolumn{8}{|l|}{ (b) Testing dataset } \\
\hline \multicolumn{8}{|l|}{ Inputs } \\
\hline Depth (ft) & 4650.000 & 7079.000 & 6357.082 & 2429.000 & 577.561 & 1.701 & -1.552 \\
\hline Oil rate (bbls/d) & 1041.000 & $18,146.000$ & 5902.082 & $17,105.000$ & 4143.083 & 0.715 & 1.090 \\
\hline Gas rate (Mscf/day) & 124.920 & 9998.450 & 2990.485 & 9873.530 & 2396.573 & 0.918 & 1.192 \\
\hline Water rate (bbls/day) & 0.000 & $10,785.000$ & 3187.902 & $10,785.000$ & 3213.975 & -0.727 & 0.662 \\
\hline Tubing diameter (inches) & 1.995 & 4.000 & 3.676 & 2.005 & 0.547 & 2.387 & -1.899 \\
\hline Oil gravity (API) & 30.000 & 37.000 & 33.338 & 7.000 & 2.152 & -0.796 & 0.391 \\
\hline Surface temperature $\left({ }^{\circ} \mathrm{F}\right)$ & 90.000 & 160.000 & 111.607 & 70.000 & 28.939 & -1.311 & 0.756 \\
\hline Bottom-hole temperature $\left({ }^{\circ} \mathrm{F}\right)$ & 157.000 & 215.000 & 202.934 & 58.000 & 17.910 & 1.368 & -1.746 \\
\hline Wellhead pressure (Psi) & 95.000 & 780.000 & 313.443 & 685.000 & 154.737 & 1.336 & 1.324 \\
\hline \multicolumn{8}{|l|}{ Output } \\
\hline Flowing bottom-hole pressure (Psi) & 1911.000 & 3217.000 & 2501.295 & 1306.000 & 324.945 & -0.751 & 0.139 \\
\hline
\end{tabular}

the FBHPs with each input using Pearson's correlation coefficient method. The definitions of $\mathrm{CC}$ and other statistical parameters are given in "Appendix A." In general, the CC value ranges from -1 to 1 , in which the values close to +1 show strong direct relationship between two parameters while the $\mathrm{CC}$ values close to zero show no relationship between two parameters and the $\mathrm{CC}$ values close to -1 show strong indirect relationship between two variables. Figure 1 shows that the FBHP is a good direct function of perforation depth, oil rate, and wellhead pressure. The CC values for perforation depth, oil rate, and wellhead pressure with FBHP are 0.65, 0.56, and 0.56, respectively. FBHP is a weak function of surface temperature and bottom-hole temperature as shown in Fig. 1. The CC values for surface and bottom-hole temperature with FBHP are 0.29 and 0.35 , respectively. However, the rest of the parameters have moderate relationship with FBHP.

\section{ANN algorithm}

In this study, ANN model is designed on the three components, namely learning algorithm, transfer function, and a signal processing element termed as neurons. Network consists of three structural layers: an input layer, a hidden layer, and an output layer. Input layer consists of nine input parameters which are well perforation depth, flowing oil rate $\left(q_{\mathrm{o}}\right)$, flowing gas rate $\left(q_{\mathrm{g}}\right)$, flowing water rate $\left(q_{\mathrm{w}}\right)$, tubing string internal diameter $(\emptyset)$, surface temperature (STM), well bottom-hole temperature (BTM), oil gravity (API), and wellhead pressure $\left(P_{\mathrm{wh}}\right)$. The learning rate and the number of neurons inside the hidden layer are the key components in ANN structure (Gitifar et al. 2013; Ashena and Thonhauser 2015). During training of the model, data were transferred from input layer to the single hidden layer and from the hidden layer to the output layer to get required output (Jorjani et al. 2008). Each layer connects with subsequent layer by connections termed as weights and auxiliary functions termed as biases (Lippman and Lippman 1987). Network functionality strongly depends on the tuning of these weights and biases (Hinton et al. 2006). At the output layer, the predicted and actual values were compared and the difference between the two calculated is called as error. To improve the predictive capability of the system, the error was transferred back to the layers to tune up the weights and

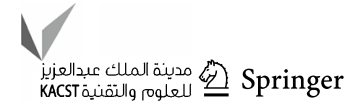


Fig. 1 Relative importance of input parameters with flowing bottom-hole pressure
Flowing Bottomhole Pressure, Psi

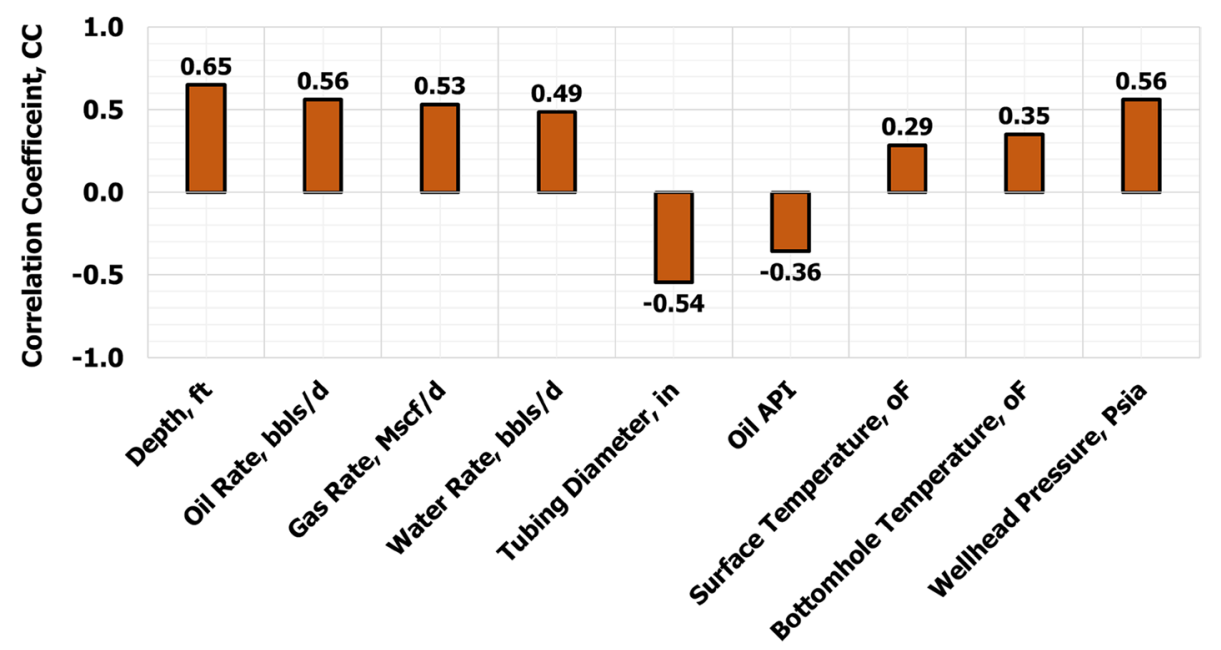

biases. This process of iteration is called as epoch. ANN then self-corrects iteratively and becomes better with progressive training runs. The final model at the end of training phase is a representation of the transfer function between the inputs and the desired output (Rao and Ramamurti 1993). In the current study, it is found that fewer number of neurons result in underfitting problem while excessive number of neurons cause more computational time with memorization or overfitting problem, which is also proved by other studies (Mohaghegh 2017).

Mathematically, the signal of neuron can be expressed by Eq. 1:

$Z_{i}=\sigma\left(\mu_{i}+b_{i}\right)$

where

$\mu_{k}=\sum_{j=1}^{N_{h}} w_{i j} x_{j}$

where $w_{i j}$ is the weight of input $\mathrm{j}$ of neuron $\mathrm{i}$ and $x_{j}$ is the input parameter, $b_{i}$ is the bias. $Z_{i}$ is the output signal of neural network, and $\sigma(x)$ is the transfer function. There are three types of transfer function, namely: piecewise linear function, sigmoidal function, and threshold function (Yang et al. 1996). The most commonly used transfer function employed in feed-forward neural network (FFNN) is sigmoidal function (Ashena and Thonhauser 2015), given by Eq. 3:

$\sigma(x)=\frac{1}{1+e^{-s x}}$

where ' $s$ ' is the slope parameter of the sigmoid function. By changing the parameter, a different slope of sigmoid function can be achieved.

In ANN, two types of models were investigated, namely radial basis function neural network function and FFNN. A comparison between these two models based on minimum averaged absolute percentage error (AAPE) and highest coefficient of determination $\left(R^{2}\right)$ was made between actual and predicted values. FFNN model was based on three structural layers, namely an input layer, a single hidden layer and an output layer. Sensitivity of number of neurons in the single hidden layer was performed by varying them in the range of 5 to 30 . The optimum number of neurons was found to be 20 , since this combination ended up in highest $R^{2}$ and lowest AAPE in training/testing phases of the modeling. Sensitivity for selecting optimum transfer function between input layer and the single hidden layer was also executed between log-sigmoidal- and tan-sigmoidal-type transfer functions. Tan-sigmoidal-type transfer function performed better than the log-sigmoidal. To get the initial weights and biases, back-propagation Levenberg-Marquardt (LM) learning algorithm was selected. To further tune the weights and biases to improve the quality of prediction, PSO a computational evolutionary algorithm was coupled with ANN.

\section{Design of hybrid PSO-ANN model}

In this study, particle swarm optimization (PSO) algorithm is used to optimize the weights and biases of the trained ANN model. PSO is a stochastic population-based evolutionary algorithm, motivated by the societal attitude of fish schooling and birds clustering (Kennedy 1997; Shi and Eberhart 1998; Abido 2002). ANN coupled with PSO has proved to be better and faster predictive tool in comparison against the conventional ANN technique (Catalao et al. 2010; Vasumathi and Moorthi 2012; Wang et al. 2015; Tariq et al. 2016; Jahed Armaghani et al. 2017; Chatterjee et al. 2017; Tariq et al. 2018a; Ethaib et al. 2018). PSO represents population of random solutions in the search space as particles assigning random velocities to them and iteratively tuning the 
fitness of the particles until the best solution called global best is achieved. PSO initializes based on predefined algorithm parameters (i.e., population, weight, cognitive parameters, etc.). It then randomly generates particle locations in the solution search space for initial objective function evaluation. Particles velocity term is given by Eq. 4:

$$
\begin{aligned}
v_{i}(n+1)= & \omega v_{i}(n)+\left\{c_{1} \times \operatorname{rand}[0,1] \times\left(p_{i}^{b}-p_{i}(n)\right)\right\} \\
& +\left\{c_{2} \times \operatorname{rand}[0,1] \times\left(p_{g b}-p_{i}(n)\right)\right\}
\end{aligned}
$$

where $\omega$ is the weight $(0 \leq w \leq 1.2), v_{i}$ particle velocity, $c_{1}$ cognitive parameter $\left(0 \leq c_{1} \leq 1.2\right), c_{2}$ cognitive parameter $\left(0 \leq c_{2} \leq 1.2\right), n$ iteration number, $p_{i}^{b}$ particle best solution, $p_{g b}$ global best solution, and $p_{i}$ particle $i$ position at any iteration.

The inertia term in the particle velocity equation $\left(w v_{i}(n)\right)$ ensures the particle moves toward its original direction, whiles its weight $(w)$ ensures the particle rate of acceleration moves toward its original direction. The cognitive component $c_{1} \times \operatorname{rand}[0,1] \times\left(p_{i}^{b}-p_{i}(n)\right)$ memorizes the particle previous best solution obtained. The social component $c_{2} \times \operatorname{rand}[0,1] \times\left(p_{\mathrm{gb}}-p_{i}(n)\right)$ moves the particle toward the global best fitness. New position for each candidate solution in the solution search space is generated by sum of the current position and velocity:

$p_{i}(n+1)=p_{i}(n)+v_{i}(n)$.

An objective function (a function that is desired to be minimized) is determined to assign the global best value, if the current best value is better than the values obtained in the previous iteration. The pseudocode for PSO-ANN algorithm is given in Table 3. After optimization, tuned weights and biases from the optimized model were retrieved.

\section{Results and discussion}

A total of 206 data points were divided randomly into two sets with the proportion of 70:30. The set with $70 \%$ of the dataset (145 data points) were used for training of the models, and the other set with $30 \%$ of the dataset (60 data points) were used to test the prediction capabilities of the trained models. The histogram plots for training and testing datasets are given in Figs. 2 and 3.

In ANN, two types of models, FFNN and RBF, were tested. During training, FFNN predicted FBHP with AAPE of $10 \%$ and $R^{2}$ of 0.90 , while RBF type of ANN predicted FBHP with AAPE of $13.6 \%$ and $R^{2}$ of 0.853 . During testing, FFNN predicted FBHP with AAPE of 12.3 and $R^{2}$ of 0.89 while RBF predicted FBHP with AAPE of $13.6 \%$ and $R^{2}$ of 0.879 , as shown in Table 4. Based on the lowest AAPE and highest $R^{2}$, FFNN was selected as better ANN type compared to RBF for the prediction of FBHP

To improve the accuracy of the model, the hybrid PSOANN algorithm is applied for the prediction of FBHP in a vertical well. On a set of random data which is $70 \%$ the total data (145 data points), PSO-ANN predicted FBHP with the AAPE of $2.0 \%$ while ANN predicted the FBHP with the AAPE of $10 \%$ as shown in Fig. 4. For the set of data which were dedicated for testing the generalization capabilities and stability of the trained model (30\% of the total data, 60 data points), PSO-ANN predicted FBHP with AAPE of $3.1 \%$, while ANN predicted FBHP with the AAPE of $12 \%$ as shown in Fig. 5.

Comparing the performance of two models; PSO-ANN and ordinary ANN, during training ANN model predicted FBHP with less AAPE than ordinary ANN, respectively, on the other hand PSO-ANN gave $R^{2}$ of 0.98 which is

Table 3 Pseudocode for PSO-ANN algorithm

\begin{tabular}{ll}
\hline Step 1 & Set number of input parameters \\
Step 2 & Initialize all parameters of ANN \\
Step 3 & Select number of hidden layers and number of neurons (sensitivity of number of neurons between 5 and 30) \\
Step 4 & Select ANN training algorithm and ANN learning rate [0,1] \\
Step 5 & Train neural network and extract weights and biases \\
Step 6 & Set parameters of PSO algorithm, population of particles, number of iterations, social acceleration, cogni- \\
& tive acceleration, and initial and final inertia weights values \\
Step 7 & Set sample search space range for each weight and bias \\
Step 8 & Input weights and biases of ANN matrix in PSO as initial population \\
Step 9 & Define AAPE as on objective function to be minimized \\
Step 10 & Check for convergence of error (minimum convergence) \\
Step 11 & Repeat the iterations until stopping criteria are met (maximum number of iterations reached, or maximum \\
Step 12 & number of inactivity reached) \\
Step 13 & Select the global optimum solution as final weights and biases matrix \\
Step 14 & Set final weights and biases in the ANN model for the prediction of FBHP
\end{tabular}



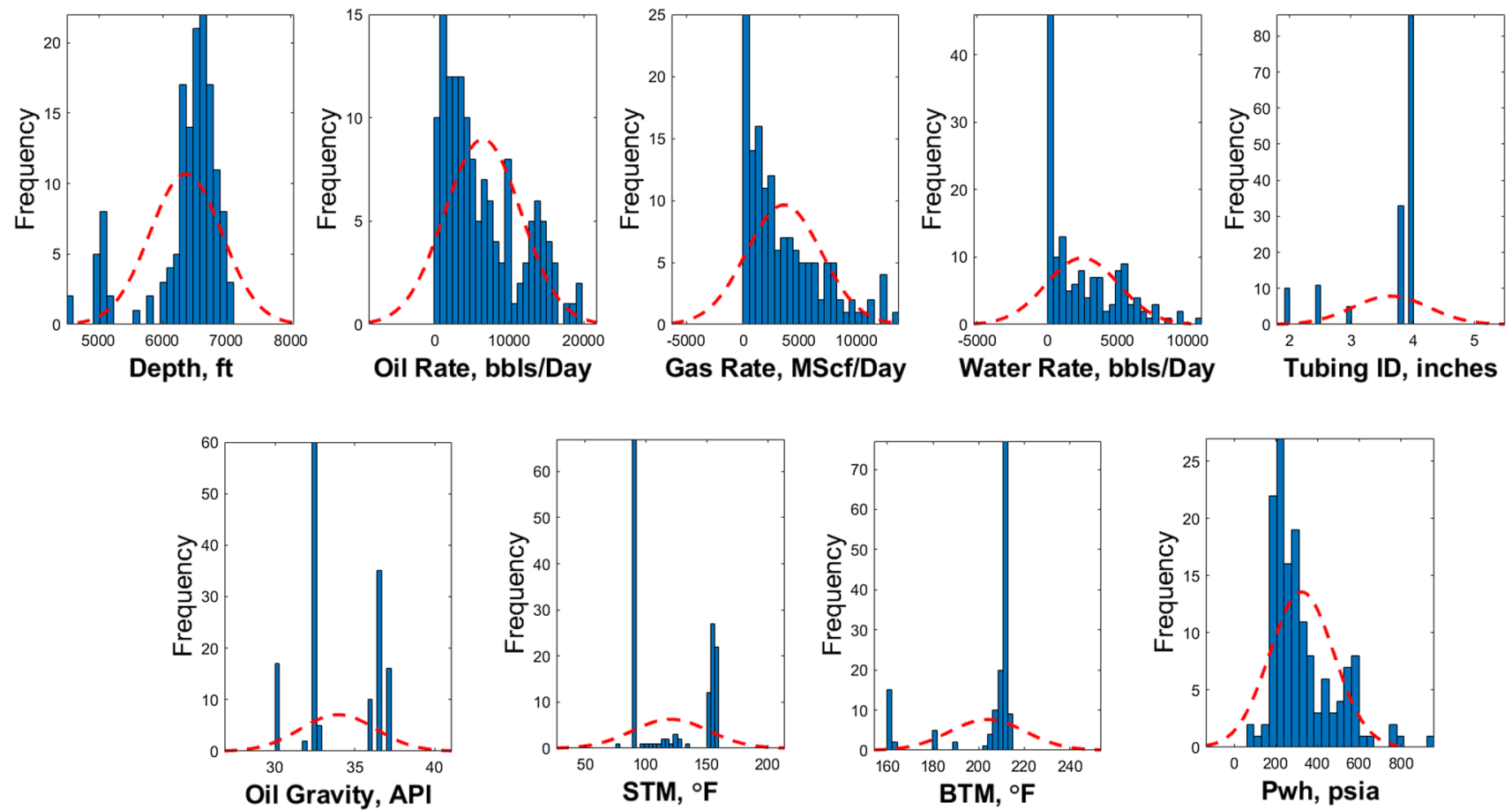

Fig. 2 Frequency histograms of training dataset (145 data points)
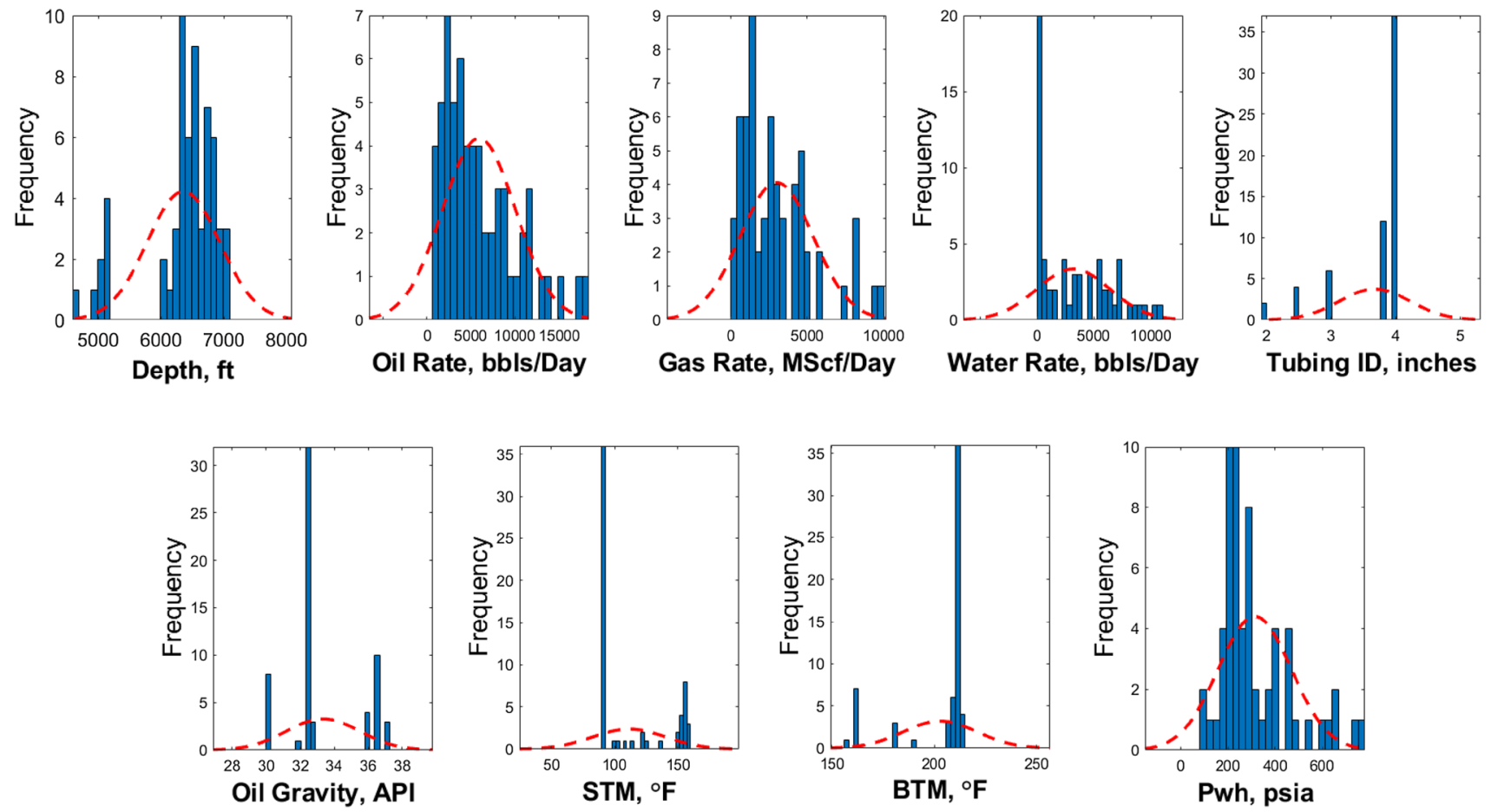

Fig. 3 Frequency histograms of testing dataset (60 data points)

higher than the $R^{2}$ produced by ordinary ANN which is 0.9 . During testing the unseen data, PSO-ANN also outperformed ANN and yielded lower AAPE and higher $R^{2}$.
Figure 6 shows the comparison cross-plots between actual and predicted FBHP for both during training and testing phases. 
Table 4 Prediction comparison of ANN types, FFNN and RBF

\begin{tabular}{llllllll}
\hline ANN type & \multicolumn{2}{l}{ Training set } & \multicolumn{3}{l}{ Testing Set } \\
\cline { 2 - 3 } & AAPE & CC & $R^{2}$ & & AAPE & CC & $R^{2}$ \\
\hline $\begin{array}{c}\text { Feed-forward neural } \\
\text { network (FFNN) }\end{array}$ & 10.0 & 0.95 & 0.90 & & 12.3 & 0.94 & 0.89 \\
$\begin{array}{c}\text { Radial basis func- } \\
\text { tion (RBF) }\end{array}$ & 13.6 & 0.924 & 0.853 & & 15.9 & 0.938 & 0.879 \\
\hline
\end{tabular}
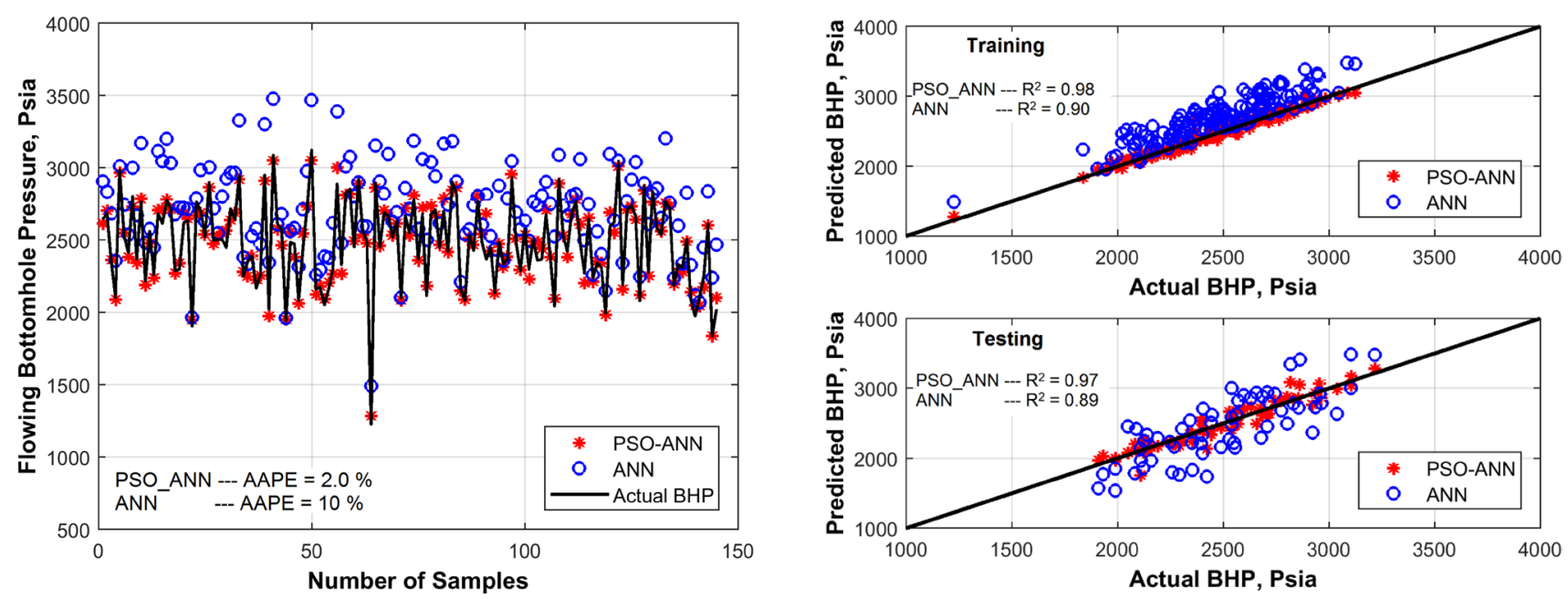

Fig. 4 FBHP prediction using optimized and unoptimized models (training dataset)

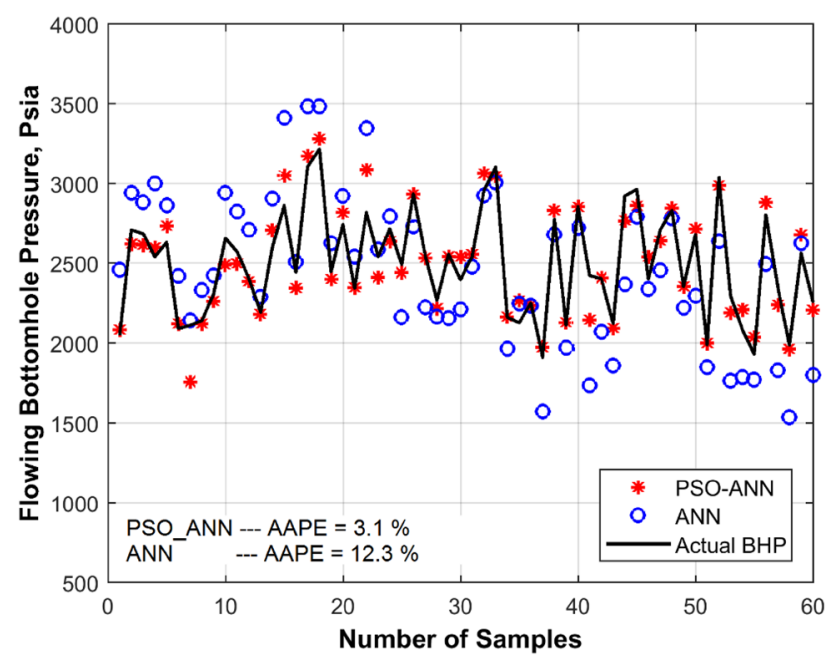

Fig. 5 FBHP prediction using optimized and unoptimized models (testing dataset)

\section{Development of an ANN-based mathematical model for FBHP prediction}

A FFNN model is created by a series of three layers, an input layer, a single hidden layer, and an output layer. Hidden layer
Fig. 6 Training and testing cross-plot of FBHP prediction using PSOANN and ANN models

neurons use their weights $w_{1}$ and biases $b_{1}$. These parameters are described by Eq. 6:

$\sigma_{L}\left(\sum_{j=1}^{N_{P}} w_{1_{j}} x_{j}+b_{1}\right)$

where $N_{P}$ is the total number of inputs, $x$ are the input parameters, and $\sigma_{L}$ is the transfer function between the input layer and the single hidden layer. The output of the whole network ' $\mu_{P}$ ' can be expressed as in Eq. 7:

$\mu_{P}(\varphi)=\sigma_{o}\left[\sum_{i=1}^{N_{h}} w_{2_{i}} \sigma_{L}\left(\sum_{j=1}^{N_{P}} w_{1_{i, j}} x_{j}+b_{1 i}\right)+b_{2}\right]$

where $\sigma_{o}$ is a transfer function between the single hidden layer and the output layer and $N_{h}$ is the hidden layer number of neurons. Weights between the input layer and the hidden layer are a matrix denoted by $w_{1}$, and weights between the hidden layer and the output layer are a vector denoted by $w_{2}$. Biases between the input layer and the hidden layer are denoted by $b_{1}$, and bias between the hidden layer and the output layer is termed as $b_{2}$.

The proposed PSO-ANN model is trained with nine input parameters which are Depth, $q_{\mathrm{o}}, q_{\mathrm{g}}, q_{\mathrm{w}}, \emptyset_{n}$, API, STM, BTM, 
and $P_{\text {wh }}$, with one hidden layer containing 20 neurons, tansigmoidal as a transfer function between input layer and hidden layer, and pure linear as a transfer function between the hidden layer and the output layer. Figure 7 shows the general architecture of the proposed model. Table 5 shows the list of learning parameters involved in the training and testing of the proposed model. An empirical correlation is developed from the proposed PSO-ANN model. An empirical correlation depends on the associated weights and biases which are listed in Table 6 . The proposed equation can be written more specifically as in Eq. 8:
Fig. 7 Architecture of PSOANN model for FBHP

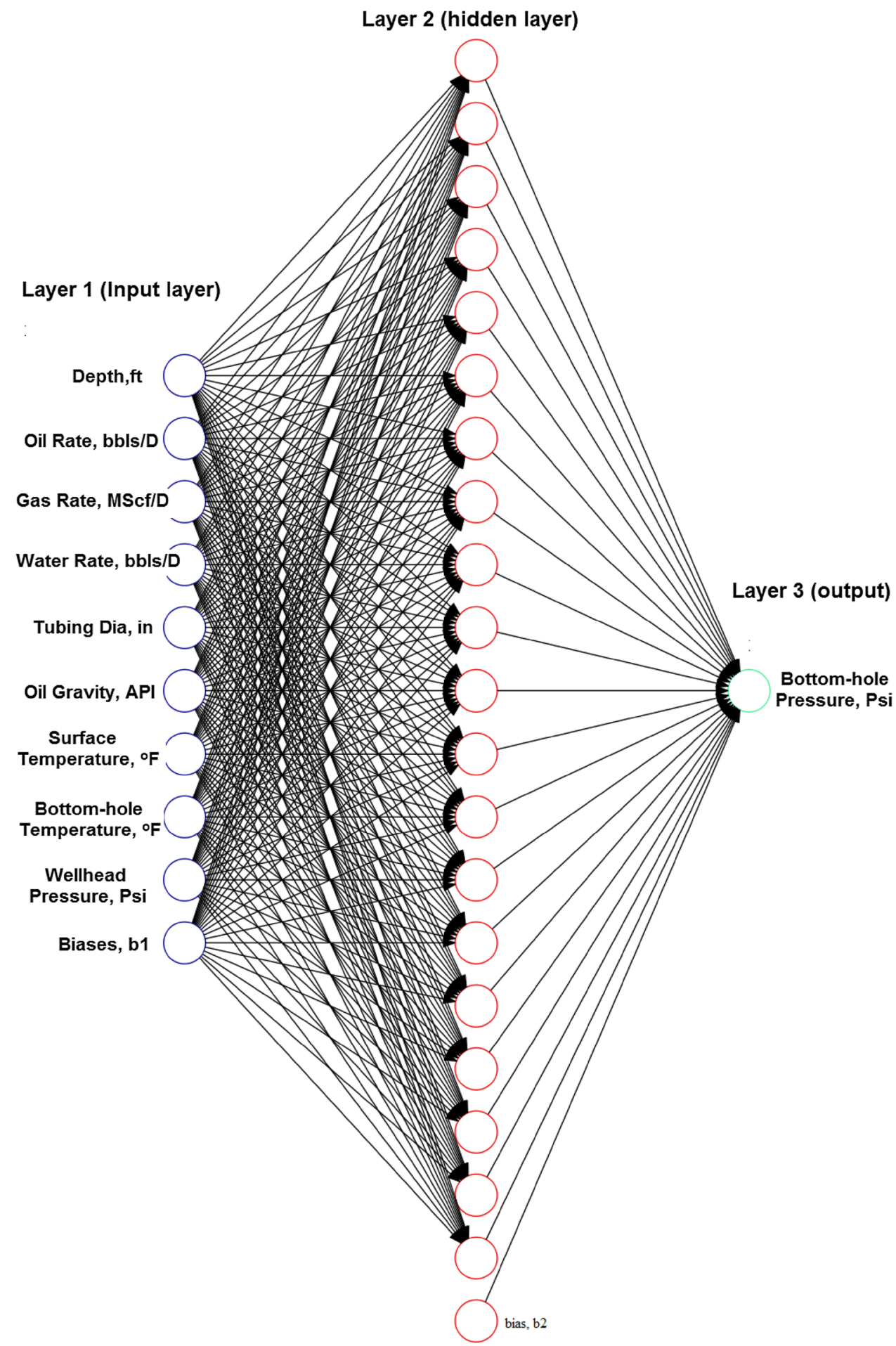


Table 5 PSO-optimized neural network architecture

\begin{tabular}{ll}
\hline Neural network parameters & Ranges \\
\hline Number of inputs & 9 \\
Number of outputs & 1 \\
Number of neurons & 20 \\
Number of hidden layer(s) & 1 \\
Training algorithm & Levenberg-Marquardt \\
Learning rate $(\alpha)$ & 0.12 \\
Hidden layer transfer function & Tan-sigmoidal \\
Outer layer transfer function & Pure linear \\
Training ratio & 0.7 \\
Testing ratio & 0.3 \\
Number of iterations & 500 \\
CPU time & $60 \mathrm{~s}$ \\
\hline
\end{tabular}

$$
\begin{aligned}
\operatorname{FBHP}_{\mathrm{n}}= & \sigma_{o}\left[\sum _ { i = 1 } ^ { N _ { h } } w _ { 2 _ { i } } \sigma _ { L } \left(w_{1_{i, 1}} \operatorname{Depth}_{n}+w_{1_{i, 2}} q_{\mathrm{o}_{n}}+w_{1_{i, 3}} q_{\mathrm{g}_{n}}\right.\right. \\
& +w_{1_{i, 4}} q_{\mathrm{w}_{n}}+w_{1_{i, 5}} \emptyset_{n}+w_{1_{i, 6}} \mathrm{API}_{n}+w_{1_{i, 7}} \mathrm{STM}_{n} \\
& \left.\left.+w_{1_{i, 8}} \mathrm{BTM}_{n}+w_{1_{i, 9}} P_{\mathrm{wh}_{n}}+b_{1_{i}}\right)+b_{2}\right]
\end{aligned}
$$

where $\sigma_{L}(x)=\left(2 / 1+e^{-2 x}\right)-1, \sigma_{o}(x)=x$

$\mathrm{FBHP}=\frac{(3217-1227)\left(\mathrm{FBHP}_{n}+1\right)}{2}+1227$

The detailed procedure to use the proposed equation is given in "Appendix B."

\section{Evaluation and validation of the proposed model to predict FBHP}

Evaluation and validation of new equation is based on published data and group trend analysis.

\section{Comparison of the proposed FBHP model with other correlations and mechanistic model}

A total of 50 data points from the published data by Peffer et al. (1988) were utilized to validate the generalization capability of the proposed PSO-ANN model. To achieve this purpose, various mechanistic and empirical models were tested on the same dataset. The mechanistic and empirical models tested were Duns and Ros (1963), Hagedorn and Brown (1965), Beggs and Brill (1973), Mukherjee and Brill (1985), Kabir and Hasan (1986), Ansari et al. (1994), and Gomez et al. (1999). Table 7 shows the list of various statistical parameters obtained from the comparison for evaluation purposes. To demonstrate the strength of the proposed model, $R^{2}$ and AAPE were used as suitable pointers of robustness. Analysis of Table 7 shows that PSO-ANN model outperforms all other investigated mechanistic and empirical models by giving less AAPE and high $R^{2}$ between actual and predicted datasets.

\section{Group trend analysis}

A group trend analysis was carried out to assess the strength of the proposed empirical model and to make sure that how effectively the proposed model captures the physical phenomenon behind each scenario. To achieve this, synthetic datasets were created, where in every set of data only one input parameter was varied from its minimum to maximum values while all other parameters were kept constant at their average values. FBHP is calculated and plotted in Figs. 8, 9, 10,11 , and 12 with different scenarios which are changing flow rate of oil, changing flow rate of gas, changing flow rate of water, changing depth of perforations, and changing GLRs with different tubing IDs.

\section{Effect of changing oil flow rate on FBHP curve}

Figure 8 shows the effect of increasing oil rate on FBHP with three different tubing IDs of sizes $2.875,3.5$, and 4.0 inches. Increase in tubing diameter reduces frictional losses which helps in increasing the flow rate. For instance, at the FBHP of $2500 \mathrm{psi}$, the 2.875 " tubing gives $8500 \mathrm{bbls} /$ day, the 3.5" tubing gives 13,200 bbls/day, and 4" tubing gives 18,700 bbls/day. Figure 8 also shows that as the oil flow rate is increasing, the FBHP is decreased to certain value and then starts increasing. The value at which FBHP is minimum at increasing oil flow rate is known as liquid loading point. It is a minimum oil rate needed to keep the well unloaded. For example, in case of 2.875 inches tubing, the minimum of $4000 \mathrm{bbls} /$ day of flow rate is needed to keep the well unloaded. This information is needed to evaluate the size of tubing which is going to be installed in a well and to determine the rate at which the well starts to deliver for a specific size of tubing. PSO-ANN model accurately predicted the effect of liquid loading on FBHP with the increase in oil production rate.

\section{Effect of changing gas flow rate on FBHP curve}

Figure 9 shows the effect of increasing gas rate on FBHP with three different tubing IDs of sizes 2.875, 3.5, and 4 inches. Figure 9 shows that as the gas flow rate is increasing, the FBHP is also increasing. This type of trend is also justified by general energy equation. PSO-ANN model predicted 


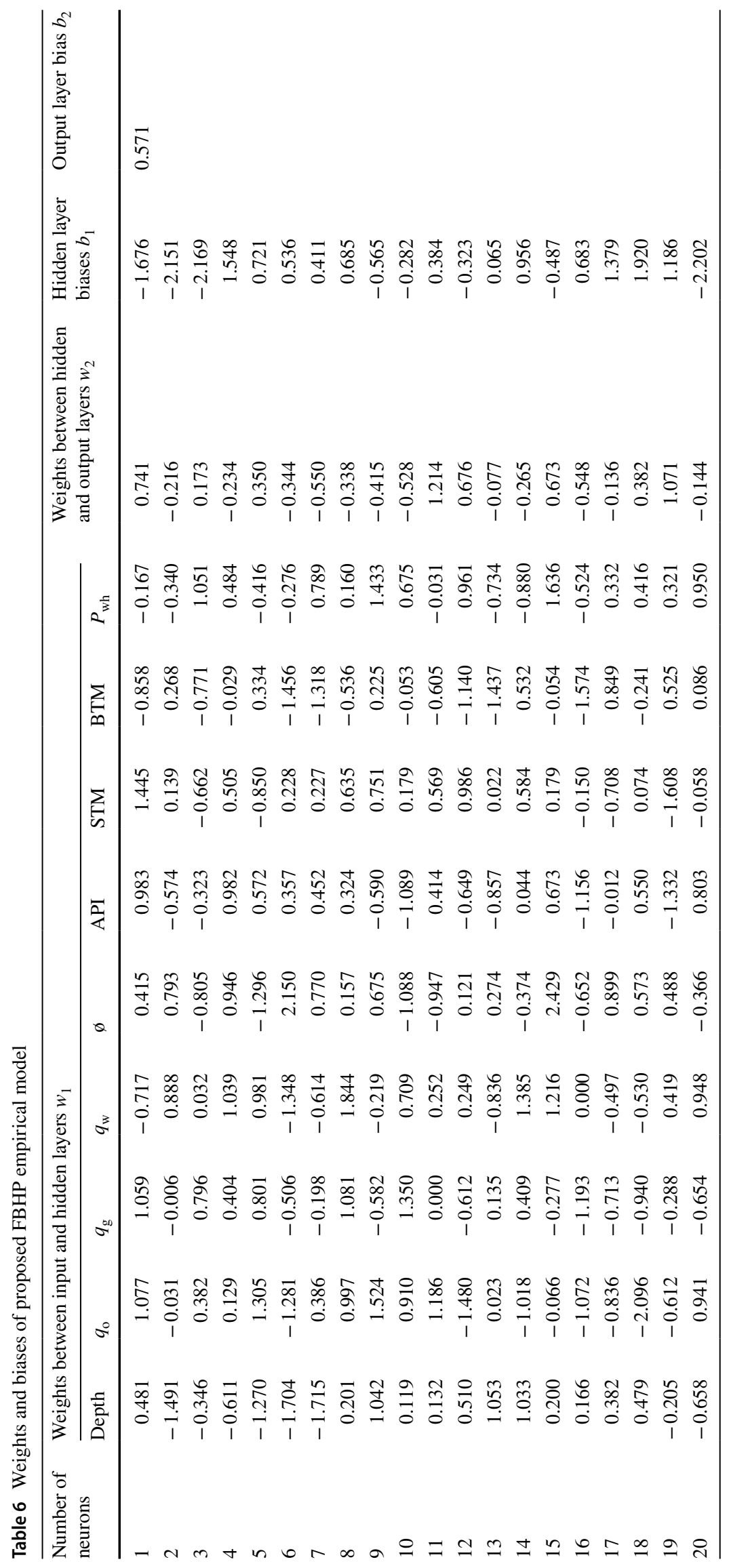


Table 7 Statistical analysis of the comparison between empirical correlations, mechanistic models, and proposed ANN model on testing dataset

\begin{tabular}{llc}
\hline Models & $R^{2}$ & AAPE \\
\hline Kabir and Hasan (1986) & 0.7502 & 19.53 \\
Ansari et al. (1994) & 0.8178 & 8.856 \\
Chokshi et al. (1996) & 0.8836 & 8.26 \\
Gomez et al. (1999) & 0.8324 & 13.95 \\
Hagedorn and Brown (1965) & 0.8508 & 9.96 \\
Duns and Ros (1963) & 0.8495 & 9.026 \\
Orkiszewski (1967) & 0.9015 & 15.65 \\
Beggs and Brill (1973) & 0.8647 & 10.56 \\
Mukherjee and Brill (1983) & 0.8792 & 7.89 \\
Proposed PSO_ANN equation & 0.983 & 2.566 \\
\hline
\end{tabular}

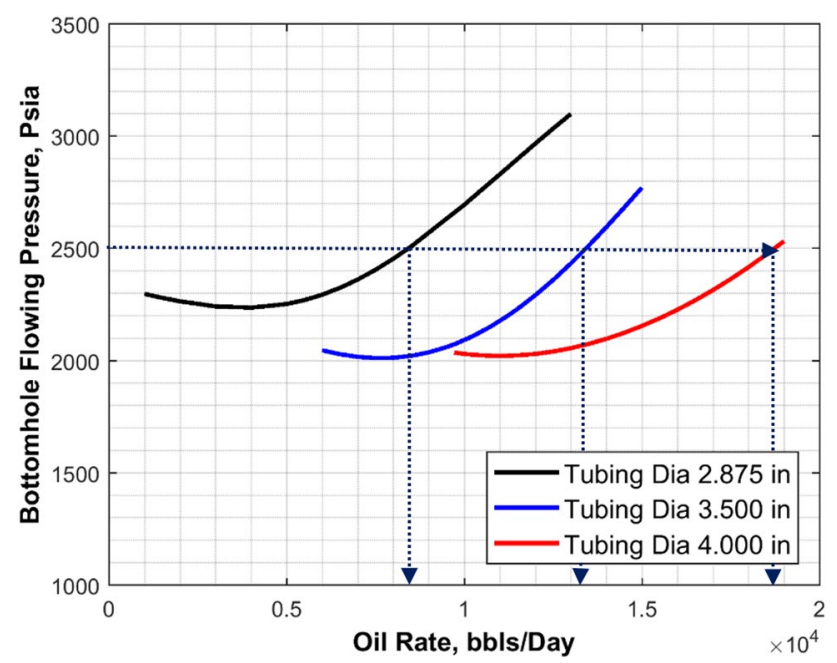

Fig. 8 Effect of changing oil rate on flowing bottom-hole pressure at tubing IDs of $2.875,3.500$ and 4.000 inches

the correct trend of increasing FBHP with the increasing gas production rate.

\section{Effect of changing water flow rate on FBHP curve}

Figure 10 shows the effect of increasing water rate on FBHP with three different tubing IDs of sizes 2.875, 3.5, and 4 inches. Again, PSO-ANN model predicted the accurate trend with the sensitivity of water rate which shows that the higher water rate gives higher FBHP.

\section{Effect of changing perforation depth on FBHP curve}

Figure 11 shows the effect of changing tubing perforation depth on FBHP. Sensitivity analysis with five different

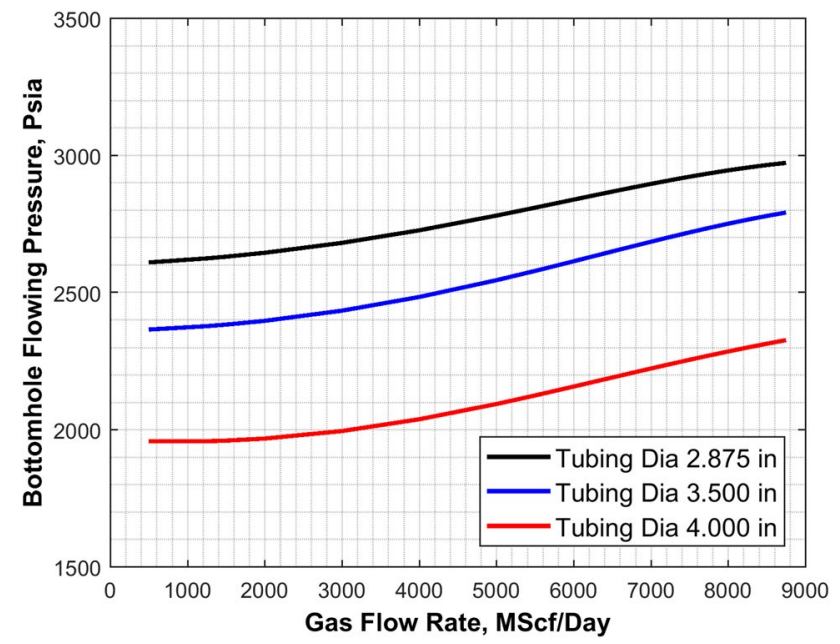

Fig. 9 Effect of changing gas rate on flowing bottom-hole pressure at tubing IDs of $2.875,3.500$ and 4.000 inches

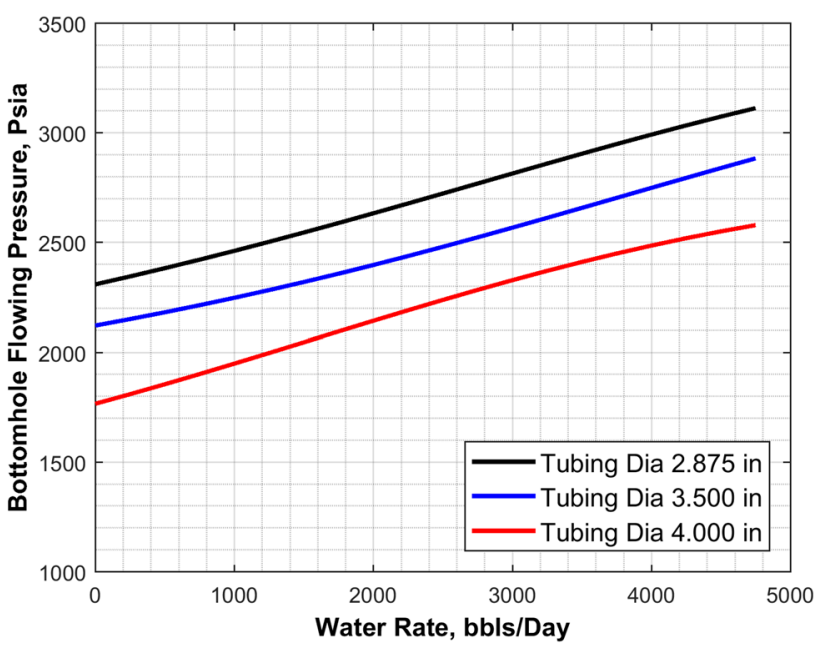

Fig. 10 Effect of changing water rate on flowing bottom-hole pressure at tubing IDs of 2.875, 3.500 and 4.000 inches

tubing IDs of sizes $1.995,2.375,2.875,3.5$, and 4.0 inches was performed. It is a well-documented fact that the pressure drop inside the vertical well is a result from three components which are hydrostatic pressure loss, frictional pressure loss, and kinetic pressure loss. For the case of vertical well, pressure losses due to kinetics are very minimal and can be neglected. Increase in perforation depth increases the hydrostatic component (function of the fluid density and depth) and therefore increases the FBHP. As can be depicted from Fig. 11, the proposed PSO-ANN model can capture the right physics which shows the increase in tubing pressure with the increase in perforation depth. 


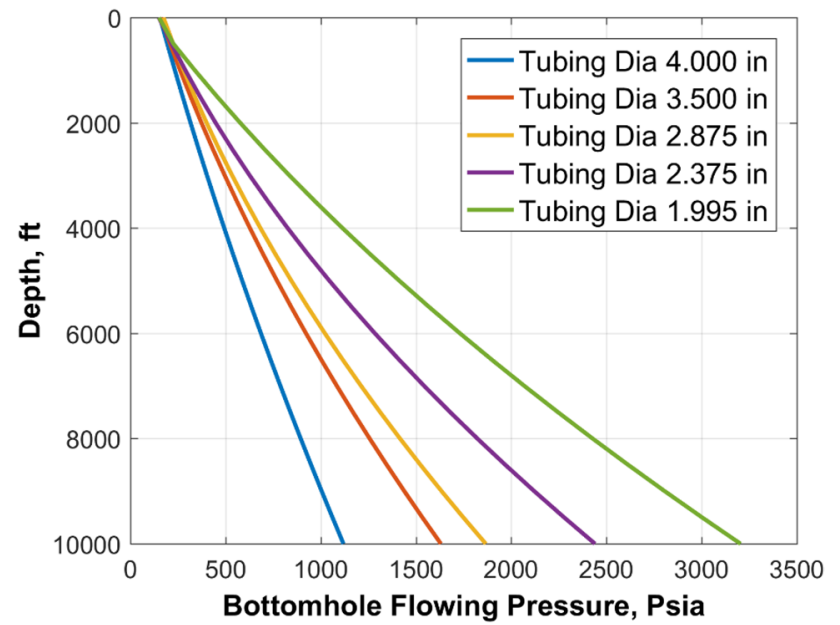

Fig. 11 Effect of changing depth on flowing bottom-hole pressure at tubing IDs of 1.995, 2.375, 2.875, 3.500 and 4.000 inches

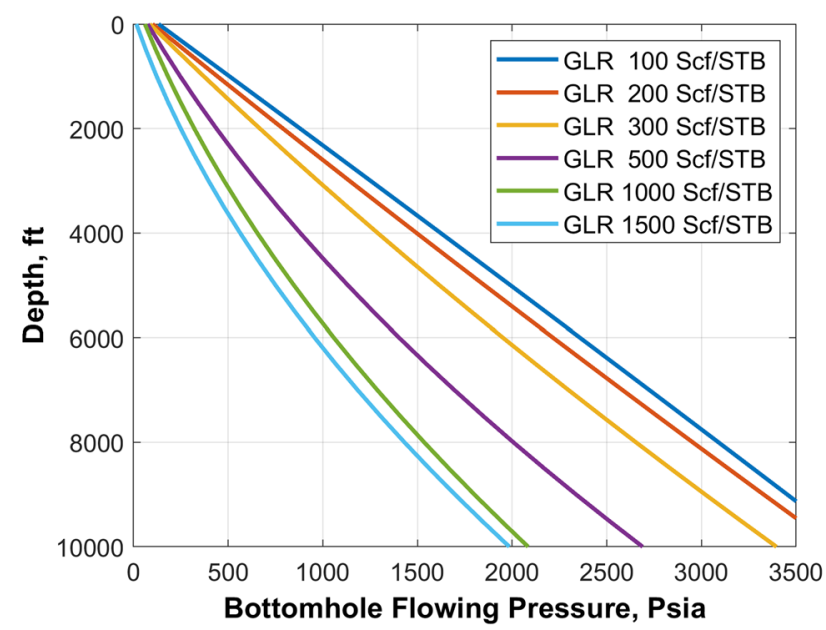

Fig. 12 Effect of changing depth with different gas-liquid ratios (GLRs) on flowing bottom-hole pressure at tubing diameter of 4.000 inches

\section{Effect of changing gas-liquid ratio (GLR) with perforation depth on FBHP curve}

Figure 12 shows the effect of changing gas-liquid ratio (GLR) with the changing depth on FBHP curve using constant tubing ID of 4.0 inches. As expected and depicted from Fig. 12, the increase in GLR results in decrease in FBHP.

\section{Conclusions}

The real-time prediction of the FBHP with real-time surface production data parameters helps in minimizing the cost of conducting sequential pressure surveys via running expensive wireline tools (having pressure-measuring gauges) inside the down-hole. The new approach avoids the need for unnecessary production interruptions to record bottom-hole pressures. Real-time assessment of FBHP allows engineer to model real-time inflow performance relationship curves (IPR), which in turn helps in identifying early well problems, and hence, prompt interventions can be taken to uphold the potential of the well. This method of estimating FBHP is also a good alternative in areas of high security concerns and adverse weather situations. The dataset used to develop proposed model is based on the true vertical depth of the tubing where the perforation was done, however the new model can also be used to measure the FBHP at the heel of the horizontal well, while the pressure drop from the toe to the heel of the horizontal well can be estimated from existing analytical equations (Ozkan et al. 1995, 1999; Su and Gudmundsson 1998) based on the dip angle that includes friction losses and gravity values in cases when perfect horizontal well was not drilled. The approach used in this study can also be extended to the inclined wells by training the model on a measured depth with the additional input of inclination angles. Based on observations and results, the following conclusions can be inferred:

1. A hybrid application of ANN and PSO served as one of the robust $\mathrm{CI}$ techniques to predict FBHP in a producing well.

2. PSO-ANN model predicted FBHP with a $R^{2}$ of 0.98 and AAPE of $2.0 \%$.

3. The proposed PSO-ANN model outperformed former mechanistic and empirical models for FBHP predictions.

4. The accurate prediction by the proposed model in a group trend analysis shows that the proposed model is capturing the right physics.

5. The new model can be applicable for a wide range of operating conditions as defined in Table $2 \mathrm{a}$.

6. From overall results, it can be said that the new model can be used as a cost-effective alternative in terms of eliminating the need for intervening the well to record FBHP by running pressure-measuring tools.

7. The new mathematical model formulated from tuned weights and biases of PSO-ANN can be utilized to predict FBHP in new wells without the need for expensive commercial software for AI training purposes.

Acknowledgement The author would like to acknowledge College of Petroleum and Geosciences, King Fahd University of Petroleum and Minerals, for providing research opportunities to produce this paper. 


\section{Compliance with ethical standards}

Conflict of interest The authors declare that they have no conflict of interest.

Open Access This article is distributed under the terms of the Creative Commons Attribution 4.0 International License (http://creativeco mmons.org/licenses/by/4.0/), which permits unrestricted use, distribution, and reproduction in any medium, provided you give appropriate credit to the original author(s) and the source, provide a link to the Creative Commons license, and indicate if changes were made.

\section{Appendix A}

Averaged absolute percentage error (AAPE) is defined as follows:

$\mathrm{AAPE}=\frac{\sum\left|\left(\mathrm{FBHP}_{\text {measured }}-\mathrm{FBHP}_{\text {predicted }}\right)\right| * \frac{100}{\mathrm{FBHP}_{\text {measured }}}}{k}$

where $\mathrm{FBHP}_{\text {measured }}$ is the measured value of FBHP and $\mathrm{FBHP}_{\text {predicted }}$ is the estimated value from the models. $\mathrm{k}$ is the total number of data points.

Correlation coefficient $\mathrm{CC}$ between two variables was defined as follows:

$$
C C=\frac{k \sum x y-\left(\sum x\right)\left(\sum y\right)}{\sqrt{k\left(\sum x^{2}\right)-\left(\sum y\right)^{2}} \sqrt{k\left(\sum b^{2}\right)-\left(\sum b\right)^{2}}}
$$

where $x$ and $y$ are two variables.

Coefficient of determination $R^{2}$ between two variables was defined as follows:

$$
R^{2}=\left(\frac{k \sum x y-\left(\sum x\right)\left(\sum y\right)}{\sqrt{k\left(\sum x^{2}\right)-\left(\sum y\right)^{2}} \sqrt{k\left(\sum b^{2}\right)-\left(\sum b\right)^{2}}}\right)^{2} .
$$

\section{Appendix B}

\section{Steps to use new mathematical model for FBHP prediction}

Step 1 Normalize input parameters between -1 and 1 . Input parameters are denoted here by ' $x$.' Normalization can be done by slope form using Eq. 10:

$$
\text { Input }_{\text {norm }}=\frac{\left(\text { Input }_{\max }-\text { Input }_{\text {min }}\right)\left(x-x_{\text {min }}\right)}{x_{\max }-x_{\min }}+\text { Input }_{\text {min }}
$$

$$
\begin{gathered}
\text { Input }_{\text {max }}=1 ; \\
\text { Input }_{\text {min }}=-1 ;
\end{gathered}
$$

$x$ is the input parameter, $x_{\min }$ is the minimum values of input parameters, and $x_{\max }$ is the maximum values of input parameters. $x_{\min }$ and $x_{\max }$ for each of the input parameters are given in Table $2 \mathrm{a}$. To perform the normalization, the following equations (Eqs. 11-19) can also be used:

Depth $_{n}=2 \times\left(\frac{\text { Depth }-4550}{7100-4550}\right)-1$

$q_{\mathrm{o}_{n}}=2 \times\left(\frac{q_{\mathrm{o}}-280}{19618-280}\right)-1$

$q_{\mathrm{g}_{n}}=2 \times\left(\frac{q_{\mathrm{g}}-33.8}{13562.18-33.8}\right)-1$

$q_{\mathrm{w}_{n}}=2 \times\left(\frac{q_{\mathrm{w}}-0}{1100-0}\right)-1$

$\emptyset_{n}=2 \times\left(\frac{\emptyset-1.995}{4-1.995}\right)-1$

$\mathrm{API}_{n}=2 \times\left(\frac{\mathrm{API}-30}{37-30}\right)-1$

$\mathrm{STM}_{n}=2 \times\left(\frac{\mathrm{STM}-76}{160-76}\right)-1$

$\mathrm{BTM}_{n}=2 \times\left(\frac{\mathrm{BTM}-157}{215-157}\right)-1$

$P_{\mathrm{wh}_{n}}=2 \times\left(\frac{P_{\mathrm{wh}}-80}{960-80}\right)-1$

Step 2 Inserting weights and biases in Eq. 8 gives normalized FBHP values. These weights and biases are given in Table 6.

Step 3 To convert FBHP value in a real space, de-normalization is required which can be done by applying Eq. 9 .

Note The results obtained using Eq. 9 will be in psi.

\section{References}

Abdulraheem A, Sabakhy E, Ahmed M, et al (2007) Estimation of permeability from wireline logs in a Middle Eastern carbonate 
reservoir using fuzzy logic. In: SPE Middle East oil and gas show and conference. Society of petroleum engineers

Abdulraheem A, Ahmed M, Vantala A, Parvez T (2009) Prediction of rock mechanical parameters for hydrocarbon reservoirs using different artificial intelligence techniques. In: SPE Saudi Arabia section technical symposium. Society of Petroleum Engineers

Abido MA (2002) Optimal design of power-system stabilizers using particle swarm optimization. IEEE Trans Energy Convers 17:406413. https://doi.org/10.1109/TEC.2002.801992

Adebayo AR, Abdulraheem A, Al-Shammari AT (2013) Promises of artificial intelligence techniques in reducing errors in complex flow and pressure losses calculations in multiphase fluid flow in oil wells. In: SPE Nigeria annual international conference and exhibition. Society of Petroleum Engineers

Adebayo AR, Abdulraheem A, Olatunji SO (2015) Artificial intelligence based estimation of water saturation in complex reservoir systems. J Porous Media 18:893-906. https://doi.org/10.1615/ JPorMedia.v18.i9.60

Adeyemi BJ, Sulaimon AA (2012) Predicting Wax Formation Using Artificial Neural Network. In: Nigeria annual international conference and exhibition. Society of Petroleum Engineers

Ahmadi MA, Galedarzadeh M, Shadizadeh SR (2016) Low parameter model to monitor bottom hole pressure in vertical multiphase flow in oil production wells. Petroleum 2:258-266. https://doi. org/10.1016/j.petlm.2015.08.001

Alimohammadi S, Sayyad Amin J, Nikooee E (2017) Estimation of asphaltene precipitation in light, medium and heavy oils: experimental study and neural network modeling. Neural Comput Appl 28:679-694. https://doi.org/10.1007/s00521-015-2097-3

Al-Shammari A (2011) Accurate prediction of pressure drop in twophase vertical flow systems using artificial intelligence. In: SPE/ DGS Saudi Arabia section technical symposium and exhibition. Society of Petroleum Engineers

Anifowose F, Labadin J, Abdulraheem A (2013) A least-square-driven functional networks type-2 fuzzy logic hybrid model for efficient petroleum reservoir properties prediction. Neural Comput Appl 23:179-190. https://doi.org/10.1007/s00521-012-1298-2

Anifowose F, Adeniye S, Abdulraheem A (2014) Recent advances in the application of computational intelligence techniques in oil and gas reservoir characterisation: a comparative study. J Exp Theor Artif Intell 26:551-570. https://doi.org/10.1080/09528 13X.2014.924577

Anifowose F, Khoukhi A, Abdulraheem A (2017) Investigating the effect of training-testing data stratification on the performance of soft computing techniques: an experimental study. J Exp Theor Artif Intell 29:517-535. https://doi.org/10.1080/09528 13X.2016.1198936

Ansari AM, Sylvester ND, Sarica C et al (1994) A comprehensive mechanistic model for upward two-phase flow in wellbores. SPE Prod Facil 9:143-151. https://doi.org/10.2118/20630-PA

Artun E (2017) Characterizing interwell connectivity in waterflooded reservoirs using data-driven and reduced-physics models: a comparative study. Neural Comput Appl 28:1729-1743. https://doi. org/10.1007/s00521-015-2152-0

Asheim H (1986) MONA, an accurate two-phase well flow model based on phase slippage. SPE Prod Eng 1:221-230. https://doi. org/10.2118/12989-PA

Ashena R, Thonhauser G (2015) Application of Artificial Neural Networks in Geoscience and Petroleum Industry. In: Cranganu C, Luchian H, Breaban ME (eds) Artificial intelligent approaches in petroleum geosciences. Springer, Cham, pp 127-166

Ashena R, Moghadasi J, Ghalambor A, et al (2010) Neural Networks in $\mathrm{BHCP}$ prediction performed much better than mechanistic models. In: International oil and gas conference and exhibition in China. Society of Petroleum Engineers
Asoodeh M (2013) Prediction of Poisson's ratio from conventional well log data: a committee machine with intelligent systems approach. Energy Sources Part A Recover Util Environ Eff 35:962-975. https://doi.org/10.1080/15567036.2011.557693

Assaleh K, Shanableh T, Kheil YA (2013) The group method of data handling-a rival of the method of stochastic approximation. Intell Control Autom 1:43-55

Awadalla M, Yousef H (2016) Neural networks for flow bottom hole pressure prediction. Int J Electr Comput Eng 6:1839. https://doi. org/10.11591/ijece.v6i4.10774

Ayoub MA, Negash BM, Saaid IM (2015) Modeling Pressure Drop in Vertical Wells Using Group Method of Data Handling (GMDH) Approach. In: ICIPEG 2014. Springer, Singapore, pp 69-78

Aziz K, Govier GW (1972) Pressure drop in wells producing oil and gas. J Can Pet Technol. https://doi.org/10.2118/72-03-04

Bageri BS, Anifowose FA, Abdulraheem A (2015) Artificial intelligence based estimation of water saturation using electrical measurements data in a carbonate reservoir. In: SPE Middle East oil and gas show and conference. Society of Petroleum Engineers

Bazargan H, Adibifard M (2017) A stochastic well-test analysis on transient pressure data using iterative ensemble Kalman filter. Neural Comput Appl. https://doi.org/10.1007/s00521-017-3264-5

Baziar S, Shahripour HB, Tadayoni M, Nabi-Bidhendi M (2016) Prediction of water saturation in a tight gas sandstone reservoir by using four intelligent methods: a comparative study. Neural Comput Appl. https://doi.org/10.1007/s00521-016-2729-2

Baziar S, Shahripour HB, Tadayoni M, Nabi-Bidhendi M (2018) Prediction of water saturation in a tight gas sandstone reservoir by using four intelligent methods: a comparative study. Neural Comput Appl 30:1171-1185. https://doi.org/10.1007/s0052 1-016-2729-2

Beggs DH, Brill JP (1973) A study of two-phase flow in inclined pipes. J Pet Technol 25:607-617. https://doi.org/10.2118/4007-PA

Bello O, Asafa T (2014) A functional networks softsensor for flowing bottomhole pressures and temperatures in multiphase production wells. In: SPE intelligent energy conference and exhibition. Society of Petroleum Engineers

Catalao JPS, Pousinho HMI, Mendes VMF (2010) Hybrid waveletPSO-ANFIS approach for short-term wind power forecasting in Portugal. IEEE Trans Sustain Energy. https://doi.org/10.1109/ TSTE.2010.2076359

Cevik A, Sezer EA, Cabalar AF, Gokceoglu C (2011) Modeling of the uniaxial compressive strength of some clay-bearing rocks using neural network. Appl Soft Comput 11:2587-2594. https://doi. org/10.1016/j.asoc. 2010.10 .008

Chatterjee S, Sarkar S, Hore S et al (2017) Particle swarm optimization trained neural network for structural failure prediction of multistoried RC buildings. Neural Comput Appl 28:2005-2016. https ://doi.org/10.1007/s00521-016-2190-2

Chen W, Di Q, Ye F et al (2017) Flowing bottomhole pressure prediction for gas wells based on support vector machine and random samples selection. Int J Hydrogen Energy 42:18333-18342. https ://doi.org/10.1016/j.ijhydene.2017.04.134

Chokshi RN, Schmidt Z, Doty DR (1996) Experimental study and the development of a mechanistic model for two-phase flow through vertical tubing. In: SPE Western regional meeting. Society of Petroleum Engineers

Davies DR, Aggrey GH (2007) Tracking the state and diagnosing down hole permanent sensors in intelligent well completions with artificial neural network. In: Offshore Europe. Society of Petroleum Engineers

Duns H Jr, Ros NCJ (1963) Vertical flow of gas and liquid mixtures from boreholes. In: Proceedings of the sixth world petroleum congress, Frankfurt, Sect II, Paper 22-PD6 
Ebrahimi A, Khamehchi E (2015) A robust model for computing pressure drop in vertical multiphase flow. J Nat Gas Sci Eng 26:13061316. https://doi.org/10.1016/j.jngse.2015.08.036

El-Sebakhy EA, Asparouhov O, Abdulraheem A-A et al (2012) Functional networks as a new data mining predictive paradigm to predict permeability in a carbonate reservoir. Exp Syst Appl 39:10359-10375. https://doi.org/10.1016/j.eswa.2012.01.157

Ethaib S, Omar R, Mazlina MKS et al (2018) Development of a hybrid PSO-ANN model for estimating glucose and xylose yields for microwave-assisted pretreatment and the enzymatic hydrolysis of lignocellulosic biomass. Neural Comput Appl 30:1111-1121. https://doi.org/10.1007/s00521-016-2755-0

Fattahi H, Gholami A, Amiribakhtiar MS, Moradi S (2015) Estimation of asphaltene precipitation from titration data: a hybrid support vector regression with harmony search. Neural Comput Appl 26:789-798. https://doi.org/10.1007/s00521-014-1766-y

Gidh YK, Purwanto A, Ibrahim H (2012) Artificial neural network drilling parameter optimization system improves ROP by predicting/managing bit wear. In: SPE intelligent energy international. Society of Petroleum Engineers

Gitifar V, Eslamloueyan R, Sarshar M (2013) Experimental study and neural network modeling of sugarcane bagasse pretreatment with $\mathrm{H}_{2} \mathrm{SO}_{4}$ and $\mathrm{O}_{3}$ for cellulosic material conversion to sugar. Bioresour Technol 148:47-52. https://doi.org/10.1016/j.biort ech.2013.08.060

Gomez LE, Shoham O, Schmidt Z et al (1999) A unified mechanistic model for steady-state two-phase flow in wellbores and pipelines. In: SPE annual technical conference and exhibition. Society of Petroleum Engineers

Govier GW, Fogarasi M (1975) Pressure drop in wells producing gas and condensate. J Can Pet Technol. https://doi. org/10.2118/75-04-03

Graves A, Liwicki M, Fernandez S et al (2009) A novel connectionist system for unconstrained handwriting recognition. IEEE Trans Pattern Anal Mach Intell 31:855-868. https://doi.org/10.1109/ TPAMI.2008.137

Hagedorn AR, Brown KE (1965) Experimental study of pressure gradients occurring during continuous two-phase flow in smalldiameter vertical conduits. J Pet Technol 17:475-484. https://doi. org/10.2118/940-PA

Helmy T, Rahman SM, Hossain MI, Abdelraheem A (2013) Non-linear heterogeneous ensemble model for permeability prediction of oil reservoirs. Arab J Sci Eng 38:1379-1395. https://doi.org/10.1007/ s13369-013-0588-Z

Hinton GE, Osindero S, Teh Y-W (2006) A fast learning algorithm for deep belief nets. Neural Comput 18:1527-1554. https://doi. org/10.1162/neco.2006.18.7.1527

Huang Z, Shimeld J, Williamson M, Katsube J (1996) Permeability prediction with artificial neural network modeling in the Venture gas field, offshore eastern Canada. Geophysics 61:422-436. https ://doi.org/10.1190/1.1443970

Jahanandish I, Salimifard B, Jalalifar H (2011) Predicting bottomhole pressure in vertical multiphase flowing wells using artificial neural networks. J Pet Sci Eng 75:336-342. https://doi.org/10.1016/j. petrol.2010.11.019

Jahed Armaghani D, Shoib RSNSBR, Faizi K, Rashid ASA (2017) Developing a hybrid PSO-ANN model for estimating the ultimate bearing capacity of rock-socketed piles. Neural Comput Appl 28:391-405. https://doi.org/10.1007/s00521-015-2072-z

Jorjani E, Chehreh Chelgani S, Mesroghli S (2008) Application of artificial neural networks to predict chemical desulfurization of Tabas coal. Fuel 87:2727-2734. https://doi.org/10.1016/j. fuel.2008.01.029
Kabir CS, Hasan AR (1986) A study of multiphase flow behavior in vertical oil wells: Part II-field application. In: SPE California regional meeting. Society of Petroleum Engineers

Karnazes PA, Bonnell RD (1982) System identification techniques using the group method of data handling. IFAC Proc 15:713-718. https://doi.org/10.1016/S1474-6670(17)63076-3

Kennedy J (1997) The particle swarm: social adaptation of knowledge. In: Proceedings of 1997 IEEE international conference on evolutionary computation (ICEC'97). IEEE, pp 303-308

Khan MR, Tariq Z, Abdulraheem A (2018) Machine learning derived correlation to determine water saturation in complex lithologies. In: SPE Kingdom of Saudi Arabia annual technical symposium and exhibition. Society of Petroleum Engineers

Lawson JD, Brill JP (1974) A statistical evaluation of methods used to predict pressure losses for multiphase flow in vertical oilwell tubing. J Pet Technol 26:903-914. https://doi.org/10.2118/4267-PA

Li X, Miskimins J, Hoffman BT (2014) A combined bottom-hole pressure calculation procedure using multiphase correlations and artificial neural network models. In: SPE annual technical conference and exhibition. Society of Petroleum Engineers

Lippman RP, Lippman RP (1987) An Introduction to Computing with Neural Nets. In: Mag A (ed) IEEE ASSP magazine. IEEE, pp 4-22

Maren AJ (1990) Introduction to neural networks. In: Maren AJ, Harston CT, Pap RM (eds) Handbook of neural computing applications. Elsevier, Amsterdam, pp 1-12

Memon PQ, Yong S-P, Pao W, Sean PJ (2014) Surrogate reservoir modeling-prediction of bottom-hole flowing pressure using radial basis neural network. In: 2014 Science and information conference. IEEE, pp 499-504

Memon PQ, Yong S-P, Pao W, Pau JS (2015) Dynamic well bottomhole flowing pressure prediction based on radial basis neural network. pp 279-292

Mohaghegh SD (2017) Shale analytics. Springer, Cham

Mohagheghian E, Zafarian-Rigaki H, Motamedi-Ghahfarrokhi Y, Hemmati-Sarapardeh A (2015) Using an artificial neural network to predict carbon dioxide compressibility factor at high pressure and temperature. Korean J Chem Eng 32:2087-2096. https://doi. org/10.1007/s11814-015-0025-y

Mukherjee H, Brill JP (1983) Liquid holdup correlations for inclined two-phase flow. J Pet Technol 35:1003-1008. https://doi. org/10.2118/10923-PA

Mukherjee H, Brill JP (1985) Pressure Drop Correlations for Inclined Two-Phase Flow. J Energy Resour Technol 107:549. https://doi. org/10.1115/1.3231233

Nooruddin HA, Anifowose F, Abdulraheem A (2013) Applying artificial intelligence techniques to develop permeability predictive models using mercury injection capillary-pressure data. In: SPE Saudi Arabia section technical symposium and exhibition. Society of Petroleum Engineers

Orkiszewski J (1967) Predicting two-phase pressure drops in vertical pipe. J Pet Technol 19:829-838. https://doi.org/10.2118/1546-PA

Osman E-SA, Ayoub MA, Aggour MA (2005) An artificial neural network model for predicting bottomhole flowing pressure in vertical multiphase flow. In: SPE Middle East oil and gas show and conference. Society of Petroleum Engineers

Ozkan E, Sarica C, Haciislamoglu M, Raghavan R (1995) Effect of conductivity on horizontal well pressure behavior. SPE Adv Technol Ser 3:85-94. https://doi.org/10.2118/24683-PA

Ozkan E, Sarica C, Haci M (1999) Influence of pressure drop along the wellbore on horizontal-well productivity. SPE J 4:288-301. https ://doi.org/10.2118/57687-PA

Peffer JW, Miller MA, Hill AD (1988) An improved method for calculating bottomhole pressures in flowing gas wells with liquid present. SPE Prod Eng 3:643-655. https://doi.org/10.2118/15655-PA

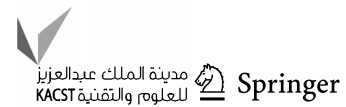


Pucknell JK, Mason JNE, Vervest EG (1993) An evaluation of Recent "mechanistic" models of multiphase flow for predicting pressure drops in oil and gas wells. In: Offshore Europe. Society of Petroleum Engineers

Rammay MH, Abdulraheem A (2016) PVT correlations for Pakistani crude oils using artificial neural network. J Pet Explor Prod Technol. https://doi.org/10.1007/s13202-016-0232-z

Rao S., Ramamurti V (1993) A hybrid technique to enhance the performance of recurrent neural networks for time series prediction. In: IEEE international conference on neural networks. IEEE, pp $52-57$

Rezaian A, Kordestany A, Sefat MH (2010) An artificial neural network approach to formation damage prediction due to Asphaltene deposition. In: Nigeria annual international conference and exhibition. Society of Petroleum Engineers

Shi Y, Eberhart RC (1998) Parameter selection in particle swarm optimization. In: Evolutionary programming. pp 591-600

Shujath Ali S, Hossain ME, Hassan MR, Abdulraheem A (2013) Hydraulic unit estimation from predicted permeability and porosity using artificial intelligence techniques. In: North Africa technical conference and exhibition. Society of Petroleum Engineers

Sonmez H, Tuncay E, Gokceoglu C (2004) Models to predict the uniaxial compressive strength and the modulus of elasticity for Ankara Agglomerate. Int J Rock Mech Min Sci 41:717-729. https://doi. org/10.1016/j.ijrmms.2004.01.011

Su Z, Gudmundsson JS (1998) Perforation inflow reduces frictional pressure loss in horizontal wellbores. J Pet Sci Eng 19:223-232. https://doi.org/10.1016/S0920-4105(97)00047-8

Takacs G (2001) Considerations on the selection of an optimum vertical multiphase pressure drop prediction model for oil wells. In: SPE/ICoTA coiled tubing roundtable. Society of Petroleum Engineers

Tariq Z, Mahmoud M (2019) New correlation for the gas deviation factor for high-temperature and high-pressure gas reservoirs using neural networks. Energy Fuels 33:2426-2436. https://doi. org/10.1021/acs.energyfuels.9b00171
Tariq Z, Al-Hashim HS, Sadeed A, Janjua AN (2016) A novel methodology to optimise the parameters of hydraulic fracturing in gas condensate reservoirs. In: International petroleum technology conference. International Petroleum Technology Conference

Tariq Z, Abdulraheem A, Khan MR, Sadeed A (2018a) New inflow performance relationship for a horizontal well in a naturally fractured solution gas drive reservoirs using artificial intelligence technique. In: Offshore technology conference Asia. Offshore Technology Conference

Tariq Z, Abdulraheem A, Mahmoud M, Ahmed A (2018b) A rigorous data-driven approach to predict Poisson's ratio of carbonate rocks using a functional network. Petrophysics—SPWLA J Form Eval Reserv Descr 59:761-777. https://doi.org/10.30632/PJV59 N6-2018a2

Tariq Z, Mahmoud M, Abdulraheem A (2019) Core log integration: a hybrid intelligent data-driven solution to improve elastic parameter prediction. Neural Comput Appl. https://doi.org/10.1007/ s00521-019-04101-3

Vasumathi B, Moorthi S (2012) Implementation of hybrid ANN-PSO algorithm on FPGA for harmonic estimation. Eng Appl Artif Intell 25:476-483. https://doi.org/10.1016/j.engappai.2011.12.005

Wang J, Zhou Q, Jiang H, Hou R (2015) Short-term wind speed forecasting using support vector regression optimized by cuckoo optimization algorithm. Math Probl Eng 2015:1-13. https://doi. org/10.1155/2015/619178

Yang Y, Rosenbaum MS (2002) No Title. Geotech Geol Eng 20:149_ 168. https://doi.org/10.1023/a:1015066903985

Yang X, Zbang J, Morris AJ (1996) Neural network model and system used for nonlinear control. IFAC Proc 29:2544-2549. https://doi. org/10.1016/S1474-6670(17)58057-X

Publisher's Note Springer Nature remains neutral with regard to jurisdictional claims in published maps and institutional affiliations 